\title{
Narrativas e relatos sobre a tatuagem no Brasil do Século XIX à década de 1970'
}

\author{
Beatriz Patriota²
}

\section{Resenha do livro:}

JEHA, Silvana. Uma história da tatuagem no Brasil: do Século XIX à década de 1970. São Paulo, Veneta, 2019.

O livro de Silvana Jeha, "Uma história da tatuagem no Brasil" (2019), é o desdobramento de uma pesquisa de Pós-Doutorado em História na Universidade Federal de São Paulo, em 2012. O interesse da pesquisadora pela tatuagem surgiu depois de sua tese de Doutorado "A galera heterogênea: Naturalidade, trajetória e cultura dos recrutas e marinheiros da Armada Nacional e Imperial do Brasil - c.1822-c.1854”, realizada no Programa de Pós-Graduação em História Social da Cultura do Departamento de História do Centro de Ciências Sociais da Pontifícia Universidade Católica - Rio de Janeiro, em 2011, que tratava sobre os marinheiros e a prática de tatuar surgiu como parte da cultura marítima.

Fonte de uma pesquisa que durou sete anos, remonta uma parte da história da tatuagem no Brasil entre o Século XIX e a década de 1970. Com uma rica pesquisa documental por meio de relatos e registros de tatuadas e sobre tatuados e de reconstruções de suas biografias ou biografemas, a pesquisadora aborda as tatuagens em marinheiros, soldados, africanos(as), imigrantes,

1 A elaboração do texto contou com apoio da Fundação de Amparo à Pesquisa do Estado de São Paulo (FAPESP), processo no $2016 / 21546-0$.

2 Programa de Pós-Graduação em Sociologia da Universidade Federal de São Carlos (PPGS - UFSCar) São Carlos - Brasil - bia.patriota@hotmail.com 
trabalhadores(as), presos(as) e religiosos(as). Cada um é retratado em um capítulo específico. O livro é dividido em nove capítulos: Portos e marítimos; Soldados; Africanas e africanos; Imigrantes; Artistas; Trabalhadores, trabalhadoras, marginalidades; Prisões; Religiosidades; e, Afetos. Conforme o modo em que foi escrito, não segue uma ordem cronológica, mas apresenta os dados por meio das temáticas e dos diferentes perfis.

A pesquisa foi feita nos arquivos do Museu Penitenciário de São Paulo, na Biblioteca Nacional, em registros da Marinha e em textos literários, apresentando um abundante material iconográfico. Sua base de dados é formada por documentos relacionados a prisões, assassinatos e mortes, incluindo arquivos médicos, policiais e páginas de jornais.

A historiadora parte do argumento de que a tatuagem já estava presente no Brasil antes da Colonização. A prática era comum em alguns povos que habitavam o território. No entanto, povos indígenas foram dizimados e as marcas praticadas por quem restou foram reprimidas, diminuindo drasticamente a tatuagem indígena.

Longe da influência indígena brasileira, a tatuagem ocidental ganhou expressividade dom os marujos, centrais para entender a história da tatuagem no Brasil. Os primeiros registros de marujos tatuados são da primeira metade do Século XIX. Mesmo período dos primeiros registros de marítimos tatuados nascidos no Brasil. Enquanto viajantes do mundo, disseminaram e popularizaram a prática como tatuados e tatuadores. Fichas do Museu Penitenciário Paulista, entre as décadas de 1920 e 1930, descrevem presos, marítimos ou não, tatuados antes da cadeia, que declararam que seus tatuadores eram marinheiros, embarcadiços ou estivadores. $\mathrm{O}$ maior número dos tatuadores profissionais registrados era composto de marujos ou atendia em áreas portuárias. As primeiras máquinas de tatuar apareceram neste circuito.

Os marinheiros temiam morrer como desconhecidos e tatuavam para serem identificados e reconhecidos em casos de naufrágio. Sinais da cruz eram marcados para identificarem os cristãos pelo receio de seus corpos serem jogados ao mar ou largados em terras distantes sem um funeral digno e um enterro religioso. Os registros da fragata de guerra Imperatriz, de 1833-1835, apontam marítimos com marcas ou "sinais". Mas Jeha acredita que havia mais navios precedentes com marujos tatuados: "marinheiros de navios negreiros e de outras embarcações estrangeiras que passaram a chegar em maior quantidade com a abertura dos portos brasileiros, em 1808" (Jeha, 2019:27). A partir do Século XVIII, a prática da tatuagem dispersou entre os marinheiros de passagem ou residentes no território brasileiro. 
Os marinheiros se locomoviam como correntes de arte espalhando a prática da tatuagem pelo mundo. Jeha apresenta a possibilidade de que a tatuagem iniciou na navegação do Mediterrâneo, antes de explodir pelos setes mares. Contando que no Século XVI, peregrinos viajavam para a Terra Santa e depois voltavam para a Europa com figuras cristãs gravadas na pele. A viagem era feita por navios, tripulados por marujos.

A cultura dos navios e portos também estava presente nos quartéis, onde os soldados se tatuavam, e nas prisões, com registros de presos que se tatuaram antes ou enquanto cumpriam sua pena. Esses corpos, disponíveis às autoridades para serem descritos e identificados, pertencem a lugares confinados e a sujeitos que buscavam uma forma de "enraizamento", longe de casa, de seus familiares e das pessoas que amavam. São esses corpos que a pesquisa da Jeha teve acesso por meio dos registros oficiais, que descreviam os "sinais", termo que englobava tatuagens, cicatrizes e outras marcas. Nas prisões, médicos estudaram e descreveram as tatuagens. A descrição de sinais era a forma de identificação de sujeitos antes da passagem do Século XIX para o XX.

Jeha também dedica um capítulo a marcas em pele de africanos e africanas que foram escravizados e trazidos à força para o Brasil. Foram analisados anúncios de fuga de escravos no acervo de periódicos da Biblioteca Nacional. Ela realiza um panorama das marcas das principais nações africanas registradas nos anúncios de fuga dos jornais do Século XIX e também das marcas de escravidão, costumeiramente feitas com ferro quente com o intuito de formar cicatrizes. Os sinais feitos ainda em suas terras são normalmente escarificações feitas segundo as tradições dos distintos povos africanos, feitos de maneira consensual. Já os carimbos, ou seja, as marcas de fogo ou de ferro, eram uma forma de punir criminosos e de identificar e controlar escravizados. $\mathrm{O}$ intuito principal era dominar e apropriar-se do sujeito escravizado e eram realizados em terra ou dento do navio para marcar o processo de escravidão desde a África. Diante das listas dos navios e dos anúncios de fuga, marcar com ferro quente se manteve como prática até 0 fim do tráfico. As marcas de ferro eram aplicadas em terras africanas onde comercializava-se escravizados; mesmas marcações eram feitas em insumos e produtos exportados como se fossem logotipos de empresas ou proprietários.

Além dessas marcas, haviam as marcas resultantes do batismo cristão, realizadas por padres em barracões ou nos navios, que geralmente eram uma ou duas cruzes na região peitoral; também há relatos de corações e âncoras nos escravizados, disponíveis em tipografias, ou de letras e números. Contudo, para os escravizados, de diferentes povos e nações, as marcas comuns aos africanos e descendentes eram as marcas de fogo. 
No Brasil, a tatuagem foi influenciada pela tatuagem portuguesa, confundida com a tatuagem marítima, já que os marinheiros portugueses eram os que mais visitavam os portos brasileiros e tripularam a Marinha Mercante e de guerra da época imperial. Além disso, foram os portugueses que povoaram como colonizadores e colonos o território, formando o maior grupo presente no Brasil. Muitos deles continuaram a pertencer às classes mais baixas da sociedade e trabalhar como calceteiros, carroceiros, lavradores, estivadores e pedreiros; se espalhando por todo o país. Entre 1906 e 1908, no Rio de Janeiro, conforme o registro do Gabinete de Identificação, dos 994 presos tatuados, 205 eram portugueses. Em Portugal, as tatuagens eram chamadas de "crismas" (denotação religiosa), "sinais" e "marcas" e a prática era comum na região do Porto. O etnólogo José de Vasconcelos descreve que a tatuagem era praticada nas aldeias portuguesas, inclusive entre mulheres. Há registros de tatuagens semelhantes entre os dois países, especialmente a religiosa, desde o Século XIX. A tatuagem em si e sua prática denotam um cunho religioso. Os registros e os desenhos portugueses se aproximam dos praticados no Brasil.

No final do Século XIX, chegou ao Brasil a prática de expor tatuados como atrações em circos, resquício dos sideshows americanos e europeus. Depois de saturar o mercado, procuraram no Brasil um lugar para lucrar com narrativas e entretenimentos que envolvessem sujeitos extremamente tatuados, apelando para uma história voltada para o primitivismo daqueles que a praticavam. O navio Advance, da linha US-Brasil Mail Company, levou ao Rio de Janeiro o tatuado George Costentenus em 1890. George se apresentou na Europa e nos Estados Unidos por aproximadamente 10 anos. Em 1904, foi a vez de Delano, tatuado e malabarista. Cada tatuado fazia uma apresentação em que contava narrativas de aventuras e fazia alguma apresentação de circo.

Já no Século XX, no Brasil, mascates de origem sírio-libanesa espalhavam-se por todo o país, como marinheiros no mar continental. Sua imagem de trabalhador e tatuado aparece em relatos sobre imigrantes turcos, sírios e libaneses, de forma estereotipada e radicalizada em que a tatuagem coaduna com a imagem bárbara. Eles também formaram uma parcela significativa dos tatuadores presentes no estado de São Paulo. As tatuagens eram bem-feitas e percebia-se uma técnica. A qualidade das tatuagens aponta para uma provável técnica. Imigrantes de todo o mundo praticavam a tatuagem no Brasil: japoneses, italianos, americanos e franceses que circulavam pelo mundo e passavam ou ficavam pelo país.

A história da tatuagem das mulheres é mais enigmática pela falta de registros e pela repressão que elas sofriam, fazendo das marcas um segredo. As tatuagens foram reveladas quando passaram pelos órgãos de repressão e registradas 
nos arquivos médicos e policiais. Mulheres infratoras eram raras - tatuadas, mais ainda. "Essas mulheres sobreviveram como puderam em meio à pobreza eà marginalização a que foram destinadas. Passado esse tempo - não completamente -, podemos interpretar suas tatuagens não como marca de infâmia, mas de coragem" (Jeha, 2019:208). Normalmente, as mulheres tatuadas pertenciam a classe trabalhadora e eram rotuladas como prostitutas, apesar da incidência mínima.

As marcas de pele também estavam presentes em africanos que vieram escravizados para o Brasil e eram usadas para facilitar o reconhecimento de fugitivos. As nações africanas possuíam diferentes padrões e estéticas, acessados pelos registros dos anúncios de fuga nos jornais do Século XIX. Normalmente, eram escarificações praticadas conforme as tradições dos povos. Além disso, havia as marcas da escravidão, chamadas de carimbos, executadas com ferro quente nos escravizados. Eram uma prática de punição, identificação e controle, em que o sujeito que a executava apropriava-se do escravizado.

"Marca" era o termo utilizado para as cicatrizes deixadas pelos ferros em brasa. A maioria delas era feita na África, na captura e no início do processo de escravidão, como apontavam as expressões: "marca de navio", "ainda boçal", "marca de consignação". Executadas em terra ou no navio, dependendo da pressa dos processos. O batismo cristão promovido por padres, em barracões ou nos navios, também gerava marcas como cruzes. Mesmo o pensamento liberal do Século XIX não conseguiu abolir as marcas nos corpos dos escravizados, que se manteve até o fim do tráfico. As marcas de ferros também eram aplicadas em objetos comercializados relacionando-os a um proprietário.

Os símbolos religiosos disparam entre as tatuagens populares. Como um amuleto, é uma mistura das práticas ocidentais da tatuagem cristã e das práticas africanas e afro-brasileiras de marcar a pele, podendo abranger até os costumes indígenas de marcar a pele. Símbolos de proteção e que remetem a religião do sujeito são comuns desde as primeiras tatuagens. Os afetos, incluindo amor, saudade, paixão, sexo e sedução, estão entre os motivos de tatuagem mais comuns.

Entre a segunda metade do Século XVIII e a primeira metade do Século $\mathrm{XX}$, a tatuagem estava presente nas camadas mais pobres. Os tatuados eram estigmatizados e considerados suspeitos e potencialmente criminosos, reflexo da influência de teorias criminalistas que apontavam a tatuagem como sinal de marginalidade.

Concomitantemente com a criminalização do tatuado, a tatuagem encontrava-se na prisão. Diferencia-se por unir-se a fatores como: perda de liberdade, exclusão social, dificuldades de ressocialização. Contudo, engloba marcações feitas antes e/ou enquanto preso. É a tatuagem mais documentada, já que os 
corpos dos presos estavam à disposição de autoridades policiais e médicas para seus registros e suas pesquisas.

Os primeiros registros são de Fernando de Noronha, dos anos 1860, quando a ilha era o destino de indesejados. Médicos escreveram teses sobre as tatuagens nas prisões, defendendo que a prática é um sinal de criminalidade. Apropriar-se do próprio corpo, uma forma de fazê-lo falar e resistir. O médico José Ignacio de Carvalho, discordando de seus colegas, concluiu que parecia não haver uma relação entre tatuagem e criminalidade tampouco entre o desenho e a infração cometida. Estudos sobre a tatuagem nos ambientes prisionais continuaram até pelo menos os anos de 1940.

A tatuagem foi uma cultura criminalizada e praticada por classes mais baixas. Os termos "delinquente" e "marginal" aparecem nos registros policiais e nos jornais para designar sujeitos criminosos ou criminalizados por serem pobres ou desempregados - sem oportunidades de se estabelecerem nas cidades. Até os anos de 1970, a tatuagem era característica do marginalizado. Desde o final do Século $\mathrm{XIX}$, as palavras "tatuado"/"tatuagem" aparecem relacionadas com crimes e mortes. Os jornais estampavam fotos dos tatuados nas páginas criminais.

Em 1959, a chegada de Knud Harald Lykke Gregersen, mais conhecido como Lucky, e a máquina de tatuar elétrica marca o elo entre o "tempo da marginalidade e a explosão da prática entre todas as camadas da população" (Jeha, 2019:17), que delineou nas décadas de 1970 e 1980 e se estabeleceu na década de 1990. Knut registrou-se como pintor e desenhista ao aportar no Brasil e é um dos únicos tatuadores profissionais citados no livro. Ele trabalhou como tatuador em Santos, em uma zona boemia e portuária, atraindo jovens da classe média de diversas cidades. Com o "renascimento da tatuagem", a tatuagem explodiu entre diferentes classes, gêneros, raças e gerações em diferentes localidades.

Jeha não encontrou registros de membros de elite tatuados de antes da década de 1970. Foi nessa época que jovens da classe médica cariocas, principalmente surfistas, começaram a viajar para Santos para tatuar-se com Lucky. A moda se alastraria por todas as classes. O "Menino do Rio", de Caetano, tema de novela, é inspirado em Petit, modelo que tatuou um dragão no braço. A mídia contribuiu para a popularização da tatuagem. A libertação do corpo pelas revoluções dos anos 1960 também foi fundamental no processo de popularização da tatuagem. A tatuagem aparece por uma série de afetos, como amor, saudade, paixão, sexo e sedução. $O$ capítulo final é dedicado a esse tema. Apresentam-se narrativas de amores familiares, passionais, eróticos, de estima ou afeição. 
Uma história da tatuagem no Brasil finda nos anos 1970, abrindo um precedente para que outros pesquisadores continuem a recuperar a trajetória dos tatuados e tatuadores no Brasil ou mesmo a forma como a tatuagem foi e é recebida, entendida, realizada e estudada em nossas terras. É uma pesquisa na área da História, que traz informações importantes para futuras análises. Separada por temas, não traz uma ordem cronológica dos fatos. Como Jeha diz na introdução: "o tempo desapareceu, décadas de 1830 e de 1960 se mesclaram".

O livro se traduz a uma pesquisa histórica documental pontual - de 1830 a 1970 - e é mais narrativo e descritivo do que analítico. Com ressalvas, carece uma análise mais firme dos dados históricos expostos e de seus momentos e contextos históricos. O livro trata-se da exposição dos materiais e fatos encontrados por Jeha, sendo uma descrição exaustiva que possui um forte apelo iconográfico.

Apesar da vasta pesquisa documental em acervos, como o Museu Penitenciário Paulista e a Biblioteca Nacional, e na literatura, diversas pesquisas que trabalham o histórico da tatuagem no Brasil não são nem ao menos citadas. Não consta os trabalhos de: Braz (2006); Costa (2004); Pires (2001; 2005; 2009); e a pesquisa de Toffoli (2005), que já havia realizado uma análise do acervo fotográfico de tatuagens do Museu Penitenciário Paulista. Decorre-se outros trabalhos a citar.

Indiscutivelmente, a crítica apresentada não deseja minimizar a relevância da pesquisa e da obra de Silvana Jeha. O material documental e iconográfico recuperado durante a investigação abre a possibilidade de novas perspectivas teóricas e empíricas sobre o tema da tatuagem na História e nas Ciências Sociais, principalmente na Sociologia, por meio da reconstrução e da exploração dos temas abordados. Ademais, o livro é acessível para além da área acadêmica e conquistou tatuadores e tatuadoras como nenhuma outra pesquisa, permitindo que o estudo alcançasse uma difusão muito maior do que qualquer outro estudo sobre o tema.

O livro resulta em uma densa contribuição de informações e dados para as futuras pesquisas sobre tatuagem no Brasil. Apresenta um conteúdo inédito e aprofundado sobre a história dos tatuados e tatuadores. Jeha pesquisou uma documentação ampla, que abarca dados de todo o Brasil, sobre um período que pouco se falava sobre a prática, quando a tatuagem não era institucionalizada nem legitimada, realizada por e para sujeitos à margem da sociedade brasileira. Ela procurou e encontrou informações nos mais diversos tipos de documentos para reconstruir essa parte da história da tatuagem. 


\section{Referências}

BRAZ, Camilo Albuquerque. Além da pele: um olhar antropológico sobre a body modification em São Paulo. Dissertação de Mestrado, Programa de Pós-Graduação em Antropologia Social, Unicamp, Campinas, 2006.

COSTA, Zelia. Do porão ao estúdio: trajetórias e práticas de tatuadores e transformações no universo da tatuagem. Dissertação de Mestrado, Antropologia Social, UFSC, Florianópolis, 2004.

JEHA, Silvana Cassab. A galera heterogênea: Naturalidade, trajetória e cultura dos recrutas e marinheiros da Armada Nacional e Imperial do Brasil, c.1822-c.1854. 2011. Tese de Doutorado, Programa de Pós-Graduação, História Social da Cultura do Departamento de História do Centro de Ciências Sociais, Pontifícia Universidade Católica Rio de Janeiro, 2011.

. Uma história da tatuagem no Brasil: do século XIX à década de 1970. São Paulo, Veneta, 2019.

PIRES, Beatriz Ferreira. Piercing, implante, escarificação, tatuagem: o corpo como suporte da arte. Dissertação de Mestrado, Artes, Instituto de Artes da UNICAMP. Campinas, s/n, 2001.

. O corpo como suporte da arte: piercing, implante, escarificação, tatuagem. São Paulo, Editora Senac, 2005.

. Corpo inciso, vazado, trasmutado: inscrições e temporalidades. São Paulo, AnnaBlume, 2009.

TOFFOLLI, Rodrigo de Oliveira. Corpos tatuados: preliminares a uma abordagem semiótica. Estudos Semióticos, São Paulo, n. 1, 2005. Disponível em: <www.fflch.usp. br/dl/semiotica/es >. Acesso em: 04 abr. 2017.

\section{Como citar esta resenha:}

PATRIOTA, Beatriz. Narrativas e relatos sobre a tatuagem no Brasil do Século XIX à década de 1970. Contemporânea - Revista de Sociologia da UFSCar, v. 10, n. 1, jan.abril 2020, pp. 357-364.

Recebido em: 04/02/2020

Aprovado em: 16/04/2020 